\title{
Numerical and Experimental Study of Catalytic Activity of Super High Temperature Ceramics
}

\author{
V.I. Sakharov ${ }^{1}$, I.V. Senyuev ${ }^{2}$, B.E. Zhestkov ${ }^{2}$ \\ ${ }^{1}$ Institute of Mechanics Lomonosov MSU, \\ Moscow, 119192, Russian Federation \\ ${ }^{2}$ Central Aerohydrodynamic Institute, \\ Moscow Region, Zhukovsky, 140180, Russian Federation \\ sakharov@imec.msu.ru
}

\begin{abstract}
Using the calculation and experimental methods, the catalytic activity of samples from super high-temperature ceramics based on hafnium diboride was determined at TsAGI VAT-104 hypersonic wind tunnel equipped with a high-frequency induction gas heater was used to study the overflow and heating of ceramic disks at surface temperatures up to $3500 \mathrm{~K}$. A significant effect of the catalytic properties of materials at ultrahigh flow rates on the heat flow was demonstrated. At the same time, for the conditions of experiments at the VAT-104 facility, in the framework of the Navier-Stokes equations, a numerical simulation of the flow of chemically nonequilibrium air plasma over these models was carried out. By comparing of the calculated and experimental values of the heat fluxes to the surface of the disk, the catalytic activity of the ceramic material is determined.
\end{abstract}

Keywords: supersonic flow, chemically nonequilibrium air plasma, catalytic activity, super high-temperature ceramics.

This work was supported by the RFBR grants No. 17-01-00054 and 18-08-00020. MSU super computer was used.

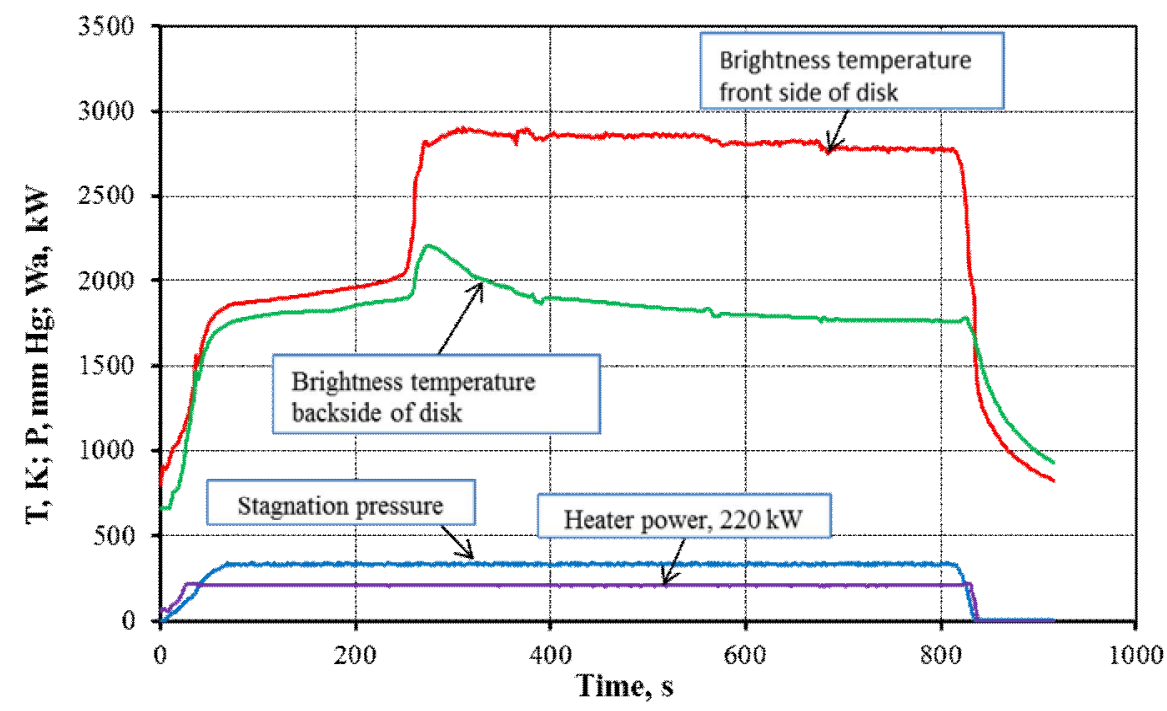

Increasing of a sample temperature due to increasing of the catalytic activity. 


\title{
Расчетно-экспериментальное исследование каталитической активности сверхвысокотемпературной керамики
}

\author{
Б.Е. Жестков ${ }^{2}$, В.И. Сахаров ${ }^{1}$, И.В. Сенюев ${ }^{2}$ \\ ${ }^{1}$ Институт механики МГУ имени М.В. Ломоносова, \\ Российская Федерация, Москва, 119192, Мичуринский проспект д. 1 \\ ${ }^{2}$ Центральный аэрогидродинамический институт им. проф. Н.Е. Жуковского, \\ Российская Федераџия, Жуковский, М.О., 140180, ул. Жуковского д. 1 \\ sakharov@imec.msu.ru
}

\begin{abstract}
Аннотация
С помощью расчетно-экспериментальной методики определена каталитическая активность образцов сверхвысокотемпературной керамики на основе диборида гафния. В ЦАГИ на гиперзвуковой аэродинамической трубе ВАТ-104, оснащенной высокочастотным индукционным подогревателем газов, проведены исследования обтекания и нагревания керамических дисков при температурах поверхности до $3500 \mathrm{~K}$. Продемонстрировано существенное влияние каталитических свойств материалов при сверхвысоких скоростях обтекания на тепловой поток. Одновременно для условий экспериментов на АДТ ВАТ-104 в рамках уравнений Навье-Стокса было проведено численное моделирование обтекания этих моделей химически неравновесной воздушной плазмой. Путем сопоставления расчётных и экспериментальных значений тепловых потоков к поверхности диска определена каталитическая активность керамического материала.

Работа выполнена при поддержке грантов РФФИ № 17-01-00054 и 18-08-00020.
\end{abstract}

Ключевые слова: сверхзвуковое течение, химически неравновесная воздушная плазма, каталитическая активность, сверхвысокотемпературная керамика.

\section{1. Введение}

При входе в атмосферу Земли со скоростями меньше 9 км/с основная доля аэродинамического нагрева поверхности спускаемого аппарата обусловлена конвективными тепловыми потоками. Достоверность расчетов тепловых потоков в первую очередь зависит от полноты и точности физической модели поля течения неравновесного воздуха в ударном и пограничном слоях. Наибольшую неопределенность в тепловой поток к поверхности затупленного тела вносит вклад гетерогенной каталитической рекомбинации атомов $\mathrm{O}$ и $\mathrm{N}$.

Понимание роли неравновесных процессов, протекающих в потоке и на поверхности, и их корректное количественное описание также важны для интерпретации данных экспериментов, полученных в высокоэнтальпийных газодинамических установках, и переноса этих данных на условия входа в атмосферу [1-18].

Широкие возможности исследований влияния кинетики газофазных и поверхностных реакций на теплообмен высокоэнтальпийных потоков газов с поверхностью и валидации компьютерных кодов предоставляют эксперименты в недорасширенных струях диссоциированного воздуха, в том числе, на установке АДТ ВАТ-104 (ЦАГИ) [7-18].

Для создания новых высокоскоростных летательных аппаратов (ВЛА) остро необходимы эрозионностойкие материалы и покрытия, выдерживающие температуры выше $2300 \mathrm{~K}$. Появился ряд работ, в том числе и отечественных, посвященных разработке высо- 
котемпературных керамических материалов, которые могут быть использованы при изготовлении наиболее теплонагруженных деталей и узлов ВЛА, таких как элементы камеры сгорания, носовой обтекатель, кромки крыла, аэродинамические рули. Необходимым этапом разработки материалов для ВЛА являются их испытания в высокоэнтальпийных установках в условиях, моделирующих условия полета. Такими установками в первую очередь являются высокочастотные плазматроны, которые позволяют исключить загрязнение поверхности материалов и испытывать их в строго контролируемых условиях. Определение каталитических свойств материалов необходимо сочетать с численным параметрическим моделированием обтекания и теплообмена образцов материала для условий экспериментов.

\section{2. Техника и методика экспериментов}

Эксперименты проводились на высокотемпературной гиперзвуковой аэродинамической трубе АДТ ВАТ-104 ЦАГИ $[1,7,15]$, позволяющей моделировать условия полета ВЛА в верхних слоях атмосферы $(60 \div 100$ км) и исследовать взаимодействие потока плазмы с поверхностью аппарата при предельно высоких тепловых нагрузках. Схема и фото АДТ ВАТ-104 показаны на рис. 1 и на рис. 2 соответственно.

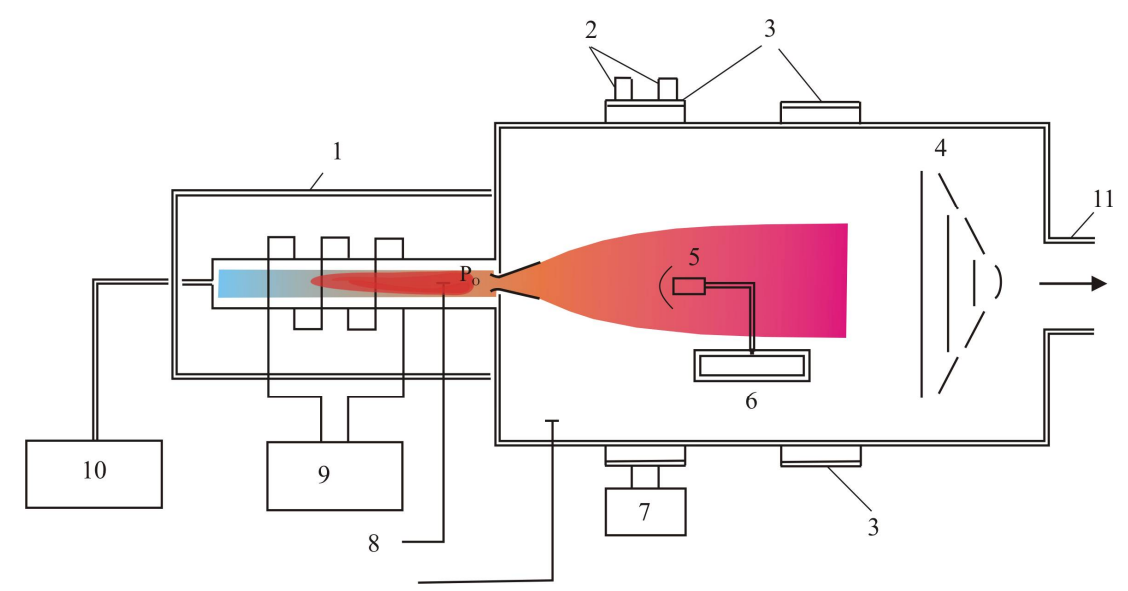

Рис. 1. Схема АДТ ВАТ-104: 1 - индукционный подогреватель; 2 - CCD камера; 3 - оптические окна; 4 - теплообменник; 5 - модель; 6 - механизм ввода; 7 - AGA; 8 - датчики давления; 9 - ВЧ генератор; 10 - подача газа; 11 - отвод в вакуумную систему

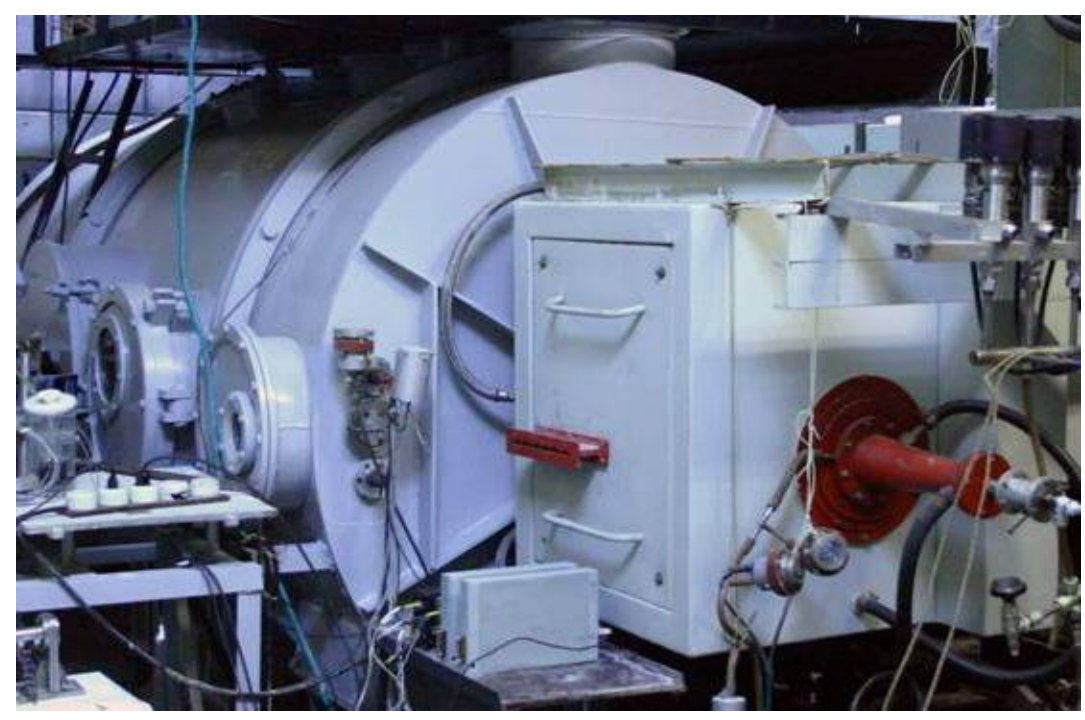

Рис. 2. Фотография установки АДТ ВАТ-104 
Нагрев газа осуществляется с помощью высокочастотного индукционного подогревателя, который позволяет получать спектрально чистый высокоэнтальпийный поток газа. Подогреватель характеризуются высокой стабильностью и повторяемостью режимов (отклонения параметров от заданных значений не превышают 3 \%). [15]. Индуктор питается от высокочастотного генератора ВЧИ-4-160/1.76. Мощность генератора по анодной цепи достигает $W_{\mathrm{a}}=240$ кВт, колебательная мощность до $W \cong 160$ кВт, частота $f=1.76$ МГц. Высокочастотный ток, текущий по индуктору, образует в объеме разрядной камеры продольное высокочастотное магнитное поле, которое создает вихревое электрическое поле, поддерживающее разряд. Плазма разряда имеет вид веретена, отжатого от стенок разрядной камеры слоем относительно холодного несветящегося газа. Нагрев газа осуществляется бесконтактным способом, обеспечивающим отсутствие загрязнений, высокую стабильность и повторяемость режимов, что крайне важно при исследовании материалов. Штатное зажигание разряда осуществляется в среде аргона при вакуумировании разрядной камеры до давления $P_{0}=5 \div 30$ Па. Затем подаётся рабочий газ, расход которого и мощность подогревателя плавно увеличиваются. Расход рабочего газа регулируется при помощи системы дросселей вручную или автоматически (режим задается программой). Время выхода на режим в зависимости от типа регулирования составляет от 10 до 60 секунд. В данной работе в качестве рабочего газа использовался воздух.

Рабочая камера представляет собой камеру Эйфеля и имеет форму цилиндра диаметром 1.6 м и длиной 4 м. К переднему торцу рабочей камеры подсоединён индукционный подогреватель с водоохлаждаемым соплом. Задний торец рабочей камеры соединен через вакуумный затвор с вакуумной емкостью. В рабочей камере размещены механизм ввода модели в поток и теплообменник, охлаждающий высокотемпературную струю газа после обтекания образца. Исследования проводились в недорасширенной струе на выходе сопла Лаваля, имеющего диаметр критического сечения $d^{*}=14.63 \mathrm{Mм}$, диаметр выходного сечения $D=53.7$ мм и угол раскрытия в сверхзвуковой части $30^{\circ}$. Давление в рабочей части BAT-104 в зависимости от количества и типов подключенных вакуумных насосов и величины расхода газа может составлять $P_{\text {рч }}=1 \div 1000$ Па. На различных расстояниях от среза сопла в струе могут быть реализованы числа Маха $\mathrm{M}=4 \div 8$.

Плазмотрон обеспечивает нагрев рабочего газа до температуры $T_{0}=5000 \div 10000 \mathrm{~K}$, (энтальпия торможения $i_{0}=10 \div 50 \mathrm{MДж/кг)} \mathrm{при} \mathrm{его} \mathrm{расходе} \mathrm{до} G=5$ г/с и полном давлении до $P_{0}=50$ кПа (0.5 бар). Максимальная продолжительность опыта ограничена возможностью охлаждения рабочей камеры и составляет $10 \div 20$ минут при давлении в форкамере трубы $P_{0}=50$ кПа и час при $P_{0} \approx 5$ кПа. Скорость потока равна $4 \div 5 \mathrm{\kappa м} / \mathrm{c}$, тепловой поток к модели $Q=0.1 \div 6 \mathrm{MBT} / \mathrm{m}^{2}$, давление перед моделью $P=1 \div 30$ мбар. При испытаниях материалов и элементов теплозащиты размером менее 70 мм удается выполнить все основные условия моделирования термохимического воздействия на элементы ВЛА, летящего со скоростью $4 \div 8$ км/с на высоте $60 \div 100$ км.

Для проведения исследования неравновесного теплообмена ВЛА разработана методика измерений яркостной температуры и излучательной способности образцов материалов при температурах до $3500 \mathrm{~K}$. Яркостная температура образца измеряется пирометром на базе цифровой ПЗС камеры VS-CTT-285/E/P-2001 на длине волны 890 нм [19] и тепловизором Тандем VS-415U на 650 нм. Спектральная температура и излучательная способность определяются по спектру теплового излучения образца, регистрируемого с помощью спектрографа Ocean Optics USB2000+ [20-21]. Значения излучательной способности и яркостной температуры позволяют определить температуру образца. Спектральная излучательная способность материала также определяется на спектрофотометре SPECORD при комнатной температуре в диапазоне длин волн от 350 до 900 нм.

Образцы в виде цилиндрических тонких дисков устанавливались на поддерживающих теплоизолирующих устройствах, что дает возможность определить тепловой поток к их поверхностям. Тепловой поток находится по распределению радиационно-равновесной яр- 
костной температуры поверхности образца. Керамический диск на базе $\mathrm{HfB}_{2}$ устанавливался на прутке из карбонитрида бора толщиной 3 мм и испытывался на двух теплонапряженных режимах (рис. 3, рис. 4). Диаметр диска 21 мм, толщина 4.7 мм. На рис. 3 представлен режим первого испытания этого образца.

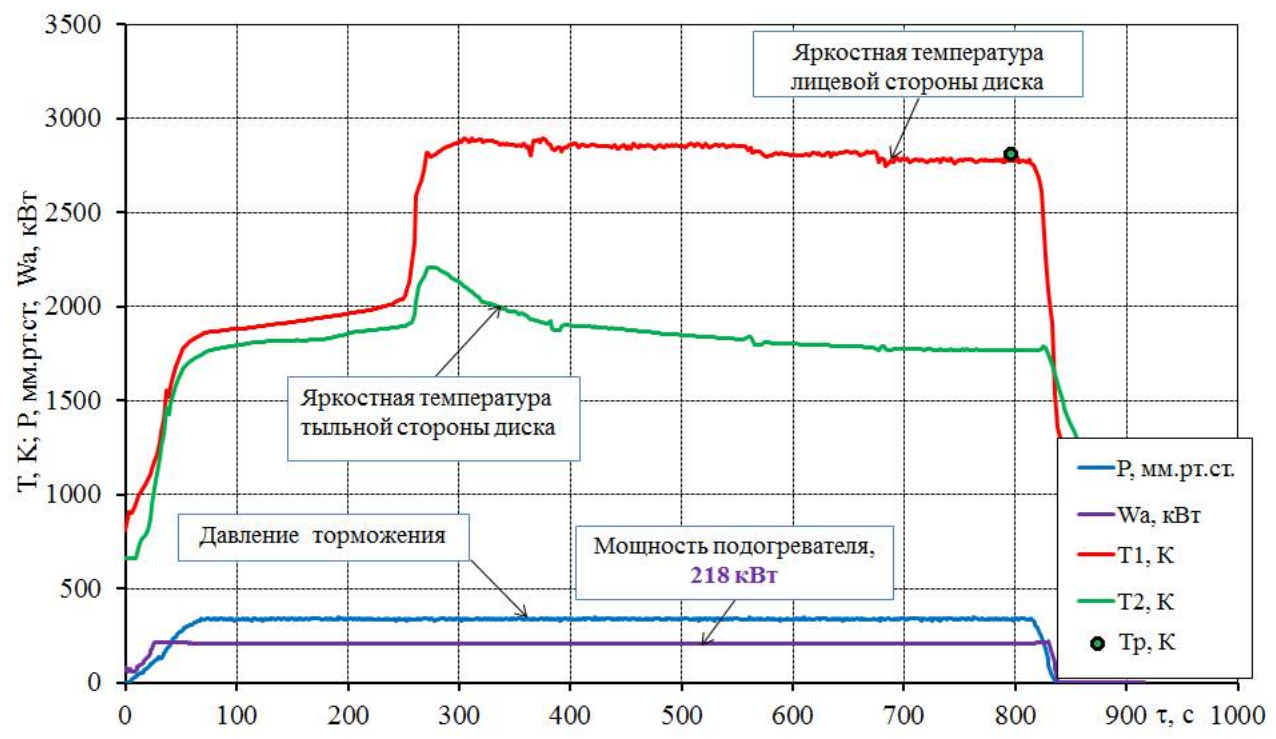

Рис. 3. Параметры испытания керамического образца.

При постоянном режиме нагревания температура лицевой поверхности образца медленно увеличивается. Достигнув значения $2055 \mathrm{~K}$, яркостная температура передней поверхности быстро возрастала до $2900 \mathrm{~K}$. Небольшие ступеньки уменьшения температуры лицевой поверхности диска вызваны перемещением диска вдоль оси струи. Расстояние от его лицевой стороны до среза сопла составляло в этих экспериментах: 56, 60, 65 и 70 мм.

В результате воздействия потока на керамический образец происходило окисление диборида гафния и карбида кремния атомарным кислородом с образованием $\mathrm{SiO}_{2}$ и белой рыхлой термобарьерной пленки $\mathrm{HfO}_{2}$. Медленное увеличение яркостной температуры с 70 по 250 секунды связано с постепенным увеличением толщины этой термобарьерной пленки $\mathrm{HfO}_{2}$. Скачкообразное увеличение температуры вызвано потерей $\mathrm{SiO}_{2}$, что приводит к скачкообразному увеличению каталитической активности пленки и, следовательно, плотности теплового потока. Высокая каталитическая активность термобарьерной пленки $\mathrm{HfO}_{2}$, повидимому, связана с новым механизмом рекомбинации. Атомы азота и кислорода встраиваются в кристаллическую решетку высокотемпературных модификаций оксида гафния $\mathrm{HfO}_{2}$ и рекомбинируют в ней. Отметим, что на образующейся термобарьерной пленке перепад температур составлял $1500 \mathrm{~K}$ при толщине пленки $\Delta \approx 0.5$ мм. Поступающий к образцу тепловой поток практически целиком излучается с поверхности пленки. За счет высокой каталитической активности пленки $\mathrm{HfO}_{2}$ удельный тепловой поток к образцу на наветренной стороне увеличился в 2.6 раза от 711 до $1845 \mathrm{BT} / \mathrm{cm}^{2}$. Константа скорости гетерогенной рекомбинации атомов азота и кислорода $K_{w}$ возросла с 4 м/с до $32.5 \mathrm{~m} / \mathrm{c}$. Тепло, выделяющееся при рекомбинации, по-видимому, полностью передается поверхности.

На рис. 4 представлен режим повторного испытания этого образца с уже образовавшейся на его поверхности высококаталитической термобарьерной пленкой. На поверхности термобарьерной пленки $\mathrm{HfO}_{2}$ сразу устанавливается высокое значение температуры, соответствующее энтальпии и давлению торможения потока. В этом испытании был выбран менее теплонапряженный режим. Давление в подогревателе составляло $P_{0}=275$ мм рт.ст., анодная мощность $W_{\text {a }}=205$ кВт. Поэтому значения температуры ниже, чем в первом испытании (рис. 3). Небольшие ступеньки увеличения температуры лицевой поверхности связа- 
ны с изменениями расстояния от диска до среза сопла от 70 до 56 мм. Масса диска в этом испытании практически не изменилась. Лицевая поверхность диска благодаря высокой каталитической активности преобразует химическую энергию потока в тепло. Круглыми маркерами на рис. 3 и рис. 4 показаны значения температуры, полученные при численном моделировании теплообмена.

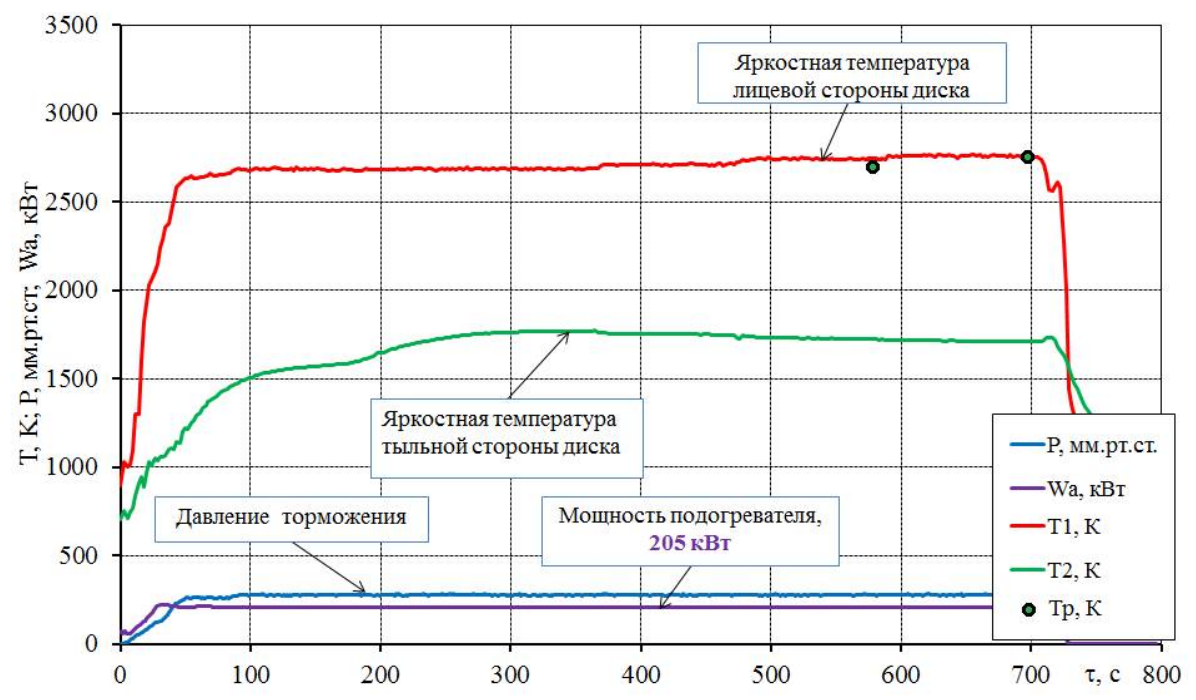

Рис. 4. Режим повторного испытания образца керамики.

\section{3. Исследование неравновесного нагревания керамических дисков}

Численное моделирование стационарного ламинарного течения воздушной плазмы в подогревателе и в недорасширенных сверхзвуковых воздушных струях для условий экспериментов на установке АДТ ВАТ-104 ЦАГИ проводилось в рамках полных уравнений Навье-Стокса и упрощенных уравнений Максвелла (для расчета переменного электромагнитного поля в подогревателе) с помощью разработанной в НИИ механики МГУ технологии численного моделирования течений высокотемпературного газа $[22,23]$. Излучение плазмы не учитывалось.

Экспериментально измеренные значения давления в подогревателе и полученные в расчетах для рассмотренных пусков хорошо согласуются друг с другом. Значения температуры в подогревателе достигает величины $12000 \mathrm{~K}$, однако значения температуры торможения в ударном слое перед исследуемым диском примерно на $3000 К$ ниже из-за потерь, в основном, в сопле и в истекающей из него недорасширенной воздушной струе.

На рис. 5 приведены сравнения экспериментально измеренных и рассчитанных значений температур на наветренной поверхности керамического диска для пуска, показанного на рис. 3. Различие расчетных и экспериментальных данных не превышает $1.5 \%$ в центральной его части, увеличиваясь к периферии до 10\%. Различие в измеренных и рассчитанных значениях температуры на периферии модели можно объяснить диффузным отражением от неровностей зеркала, через которое пирометр фиксирует излучение в эксперименте.

Расчеты неравновесного обтекания и теплообмена проводились при ряде значений константы скорости гетерогенной рекомбинации атомов $K_{w}$ для лицевой поверхности диска в пределах от 4 до 32.5 м/с. Значения температуры поверхности дисков высокотемпературной керамики и этих же дисков с покрытием МАИ Д5 при идентичных условиях испытаний при $T_{w}<2000 \mathrm{~K}$ совпали в пределах погрешности $3 \%$. Это позволяет принять значение константы $K_{w}$ для задней стороны диска таким же, как у покрытия МАИ Д5 [7], $K_{w}=4 \mathrm{~m} /$ с. Сопоставление результатов расчета и эксперимента показало, что наилучшее 
согласие значений теплового потока наблюдается при $K_{w}=32.5 \mathrm{~m} / \mathrm{c}$. Константа $K_{w}$ для лицевой поверхности диска определялась также по методике работы [14]. Полученное значение составляет $K_{w}=31 \mathrm{~m} / \mathrm{c}$. Согласие результатов по обеим методикам хорошее. Отметим, что значение излучательной способности лицевой поверхности дисков, определенное в эксперименте, составляет $\varepsilon=0.5$. Термодинамическая температура лицевой поверхности диска высокотемпературной керамики при величине яркостной температуры $2700 \mathrm{~K}$ и $\varepsilon=0.5$ составляет $3250 \mathrm{~K}$.

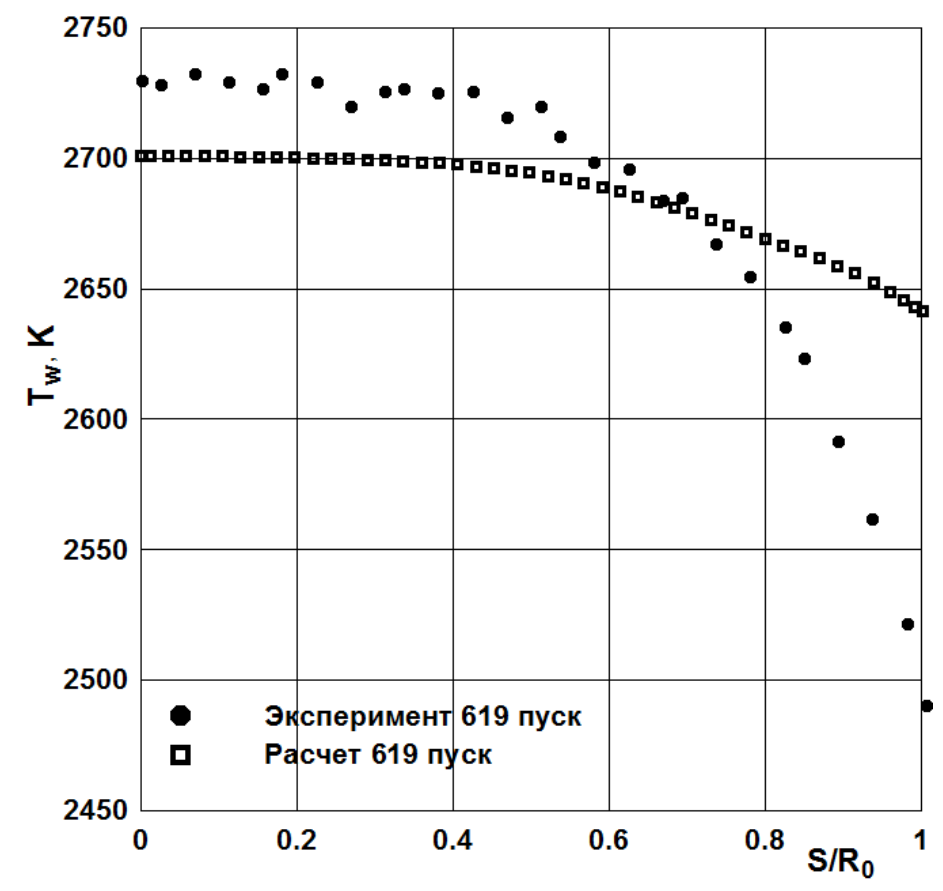

Рис. 5. Сравнение распределений температур по наветренной стороне диска в эксперименте для пуска 619 и расчете

Сопоставление результатов расчета и эксперимента по определению теплового потока к лицевой стороне диска представлено в табл. 1. Благодаря образованию термобарьерной пленки, практически не имеет место перетекание тепла с передней поверхности диска, что позволяет сравнивать тепловые потоки в расчете и эксперименте. Отличие в тепловых потоках не превышает $4 \%$.

Таблицุа 1

Сопоставление результатов расчета и эксперимента

\begin{tabular}{|c|c|c|c|c|c|}
\hline Пуск & Режим испытания & $\begin{array}{l}\text { Расстояние до } \\
\text { среза сопла, мм }\end{array}$ & Время, с & Условия & $\begin{array}{c}\text { Тепловой поток } \\
\text { к диску, Вт }\end{array}$ \\
\hline \multirow{2}{*}{$619(1)$} & \multirow{2}{*}{$\begin{array}{c}\text { Первичное } \\
\text { испытание (Рис. 3) }\end{array}$} & \multirow{2}{*}{70} & \multirow{2}{*}{798} & Эксперимент & 935 \\
\hline & & & & Расчет & 951 \\
\hline \multirow{2}{*}{$622(2)$} & \multirow{4}{*}{$\begin{array}{c}\text { Повторное } \\
\text { испытание (Рис. 4) }\end{array}$} & \multirow{2}{*}{60} & \multirow{2}{*}{578} & Эксперимент & 940 \\
\hline & & & & Расчет & 901 \\
\hline \multirow{2}{*}{$622(2)$} & & \multirow{2}{*}{56} & \multirow{2}{*}{696} & Эксперимент & 951 \\
\hline & & & & Расчет & 959 \\
\hline
\end{tabular}

На рис. 6-9 приведены параметры течения вдоль оси симметрии течения и дано сравнение с экспериментом по давлению в подогревателю (рис. 8). 


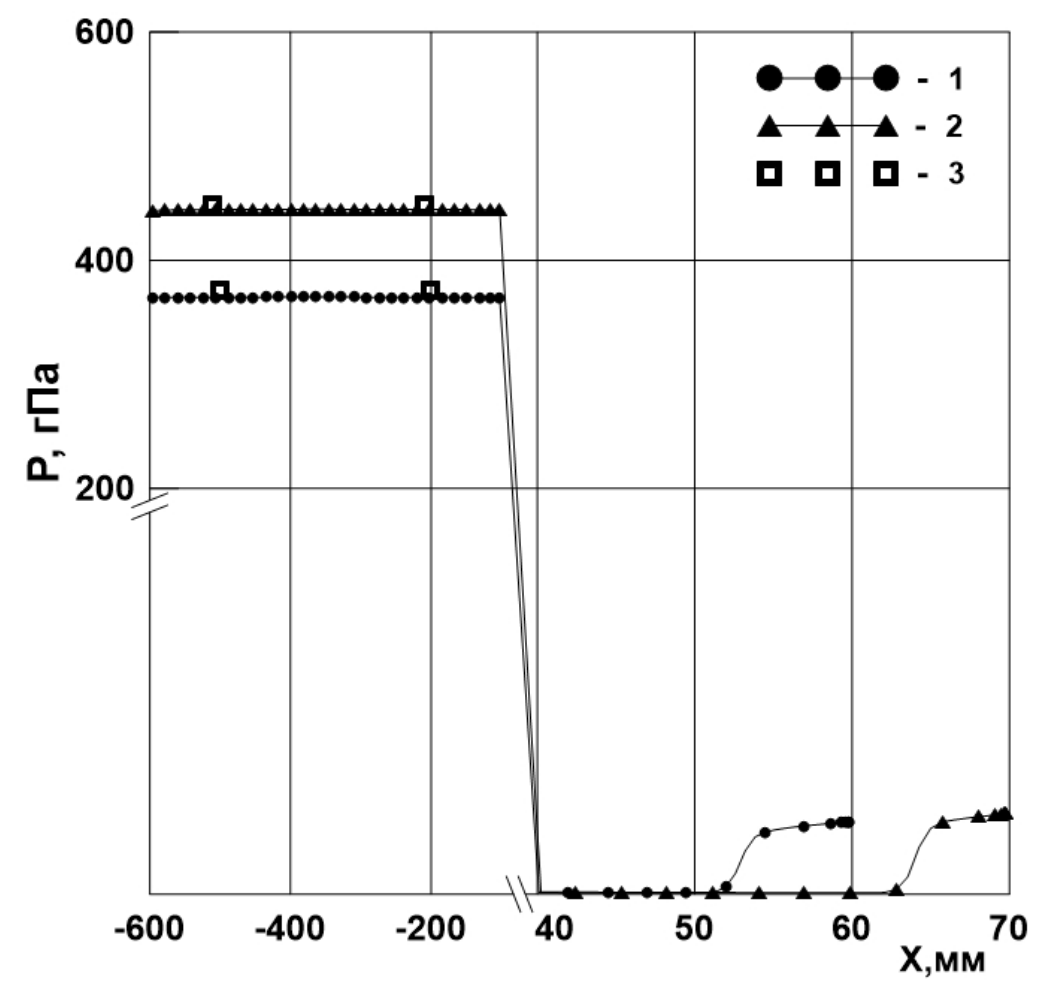

Рис. 6. Распределение давления вдоль оси симметрии течения: 2,1 - соответствуют режимам 622(1) и 619 соответственно (таблица 1); 3 - экспериментальные значения

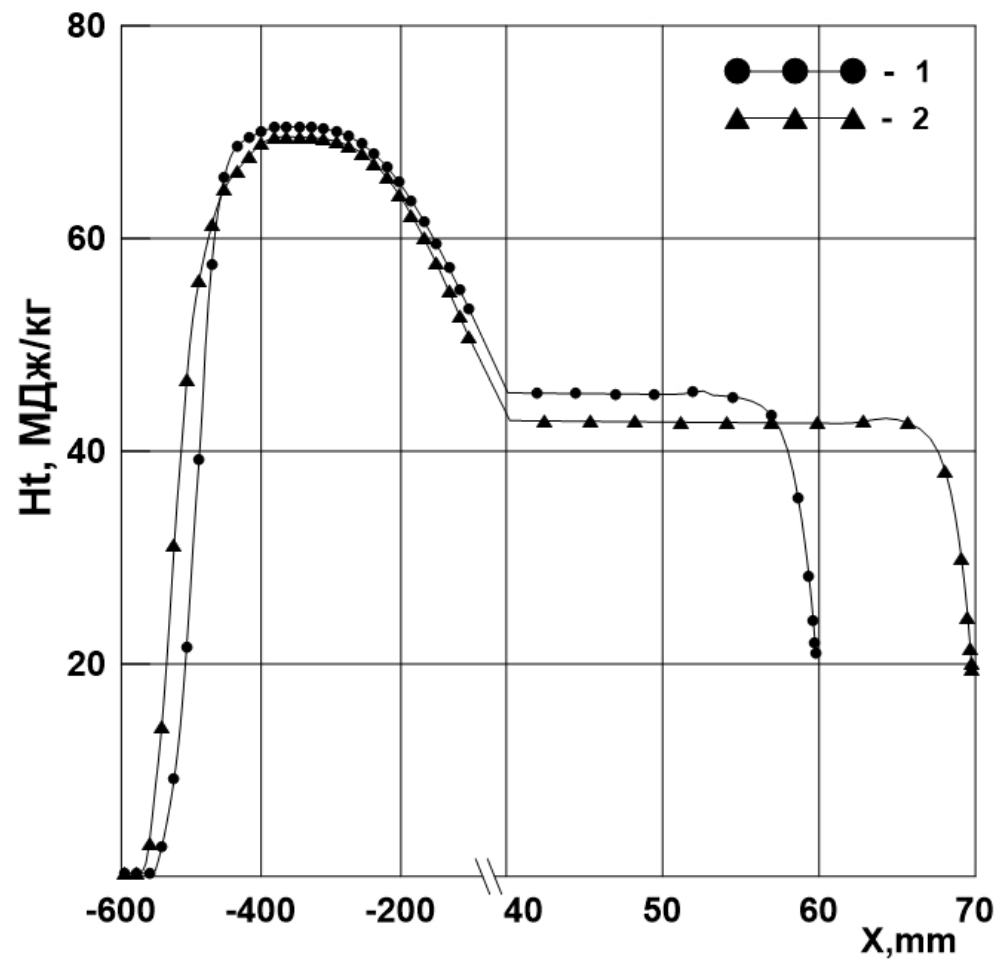

Рис. 7. Распределение энтальпии вдоль оси симметрии течения: 2,1 - соответствуют режимам 622(1) и 619 соответственно (таблица 1) 


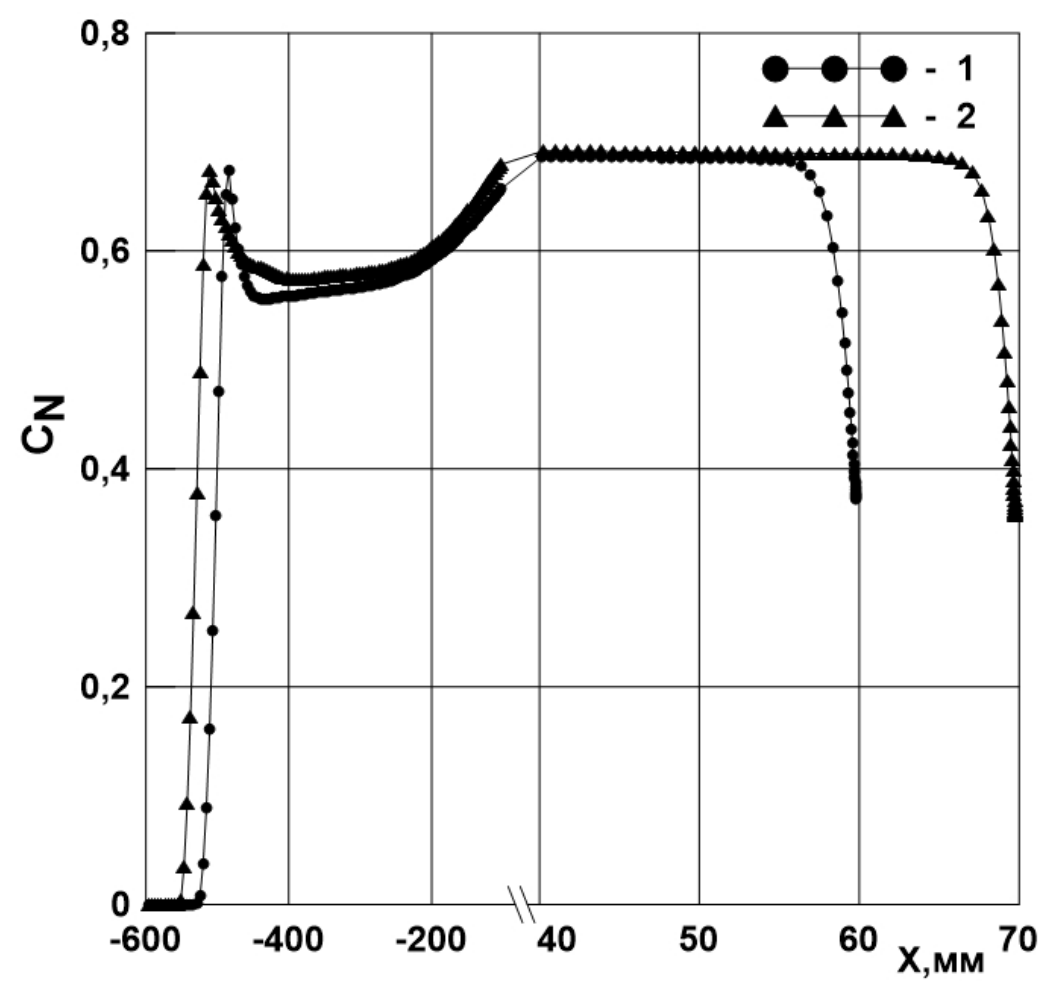

Рис. 8. Распределение массовой концентрации атомарного азота вдоль оси симметрии течения: 2,1 - соответствуют режимам 622(1) и 619 соответственно (таблица 1)

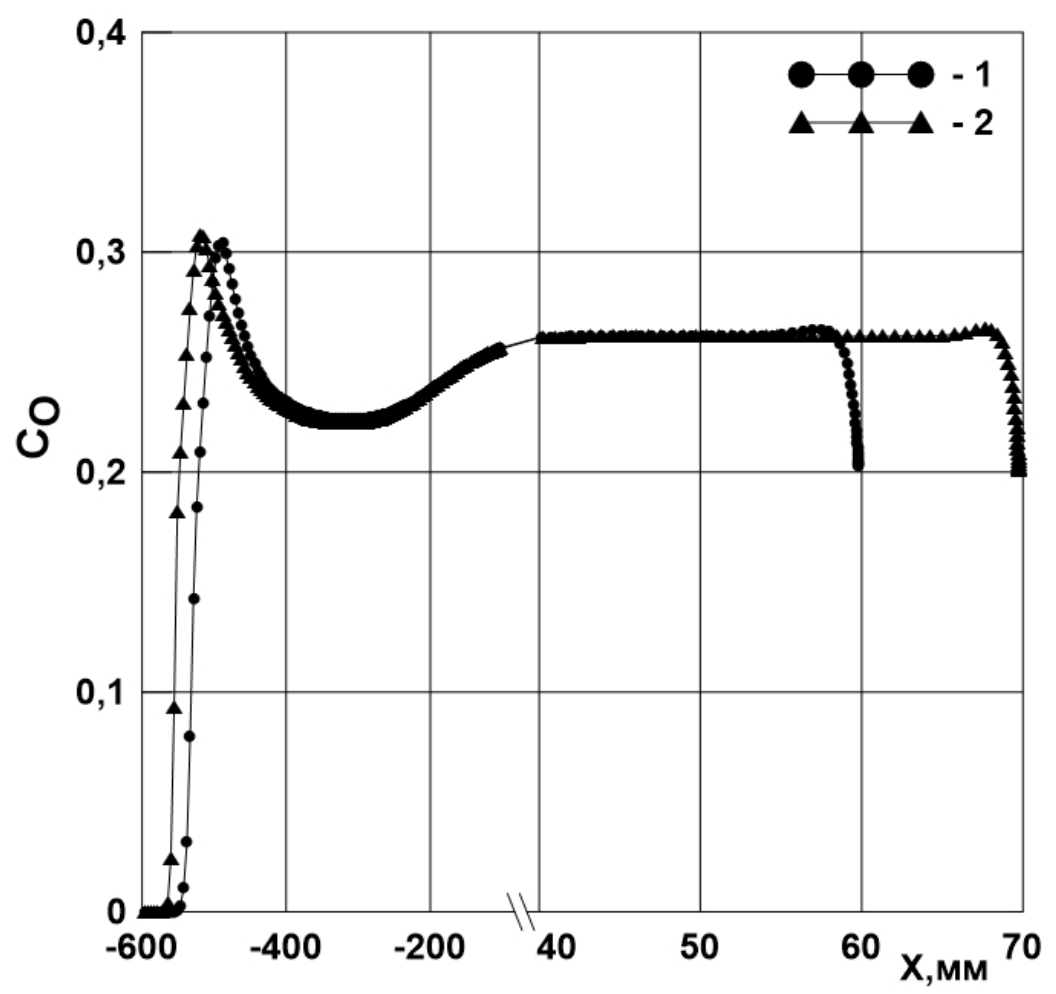

Рис. 9. Распределение массовой концентрации атомарного кислорода вдоль оси симметрии течения: 2,1 - соответствуют режимам 622(1) и 619 соответственно (таблица 1) 


\section{4. Заключение}

Проведены экспериментальные исследования обтекания и измерены температура и тепловые потоки на поверхности диска из сверхвысокотемпературной керамики на основе диборида гафния $\mathrm{HfB}_{2}$ в аэродинамической трубе ВАТ-104 ЦАГИ в химически неравновесном высокоэнтальпийном сверхзвуковом потоке воздушной плазмы.

В рамках уравнений Навье-Стокса и химически неравновесной модели газовой среды проведено численное моделирование течения в подогревателе, сверхзвуковом сопле и в рабочей части АДТ ВАТ-104 ЦАГИ, а также обтекания диска из керамики для условий экспериментов.

Выполнены параметрические численные исследования неравновесного теплообмена диска с теплоизолированной поверхностью при различных значениях каталитической активности его поверхности.

Сравнение измеренных в экспериментах и полученных в расчетах тепловых потоков к диску позволило определить каталитическую активность исследуемых образцов сверхвысокотемпературной керамики при температуре $3250 \mathrm{~K}$. Полученное значение константы скорости гетерогенной рекомбинации атомов составляет $K_{w}=32.5 \mathrm{~m} / \mathrm{c}$.

Работа выполнена при поддержке грантов РФФИ № 17-01-00054 и 18-08-00020 с использованием Суперкомпьютерного комплекса МГУ.

\section{Литература}

1. Василевский Э.Б., Жестков Б.Е., Сахаров В.И. Численное моделирование и эксперимент на индукционном плазмотроне АДТ ВАТ-104 // Ученые записки ЦАГИ, 2016. Т. XLVII, № 5. C. $3-14$.

2. Гордеев А.Н., Колесников А.Ф., Сахаров В.И. Течение и теплообмен в недорасширенных струях индукционного плазмотрона // Известия РАН, Механика жидкости и газа. 2011. № 4. C. $130-142$.

3. Колесников А.Ф., Гордеев А.Н., Сахаров В.И. Теплообмен в недорасширенных неравновесных струях углекислого газа: эксперимент на индукционном плазмотроне численное моделирование и экстраполяция на условия входа в атмосферу Марса //«Физико-химическая кинетика в газовой динамике». 2014. T. 15. Вып. 4. http://chemphys.edu.ru/pdf/2014-11-28-005.pdf

4. Колесников А.Ф., Сахаров В.И. Подобие теплообмена модели в недорасширенных струях диссоциированного воздуха в ВЧ-плазмотроне и при обтекании сферы высокоскоростным потоком в земной атмосфере. // Изв. РАН. МЖГ. 2016. №3. С. 115-120.

5. Гордеев А.Н., Колесников А.Ф., Сахаров В.И. Течение и теплообмен в недорасширенных неравновесных струях углекислого газа: эксперимент и численное моделирование // Теплофизика высоких температур. 2015, Т. 53, № 2. С. 284-290.

6. Колесников А.Ф., Гордеев А.Н., Конов А.Н., Лукомский И.В., Мысова В.М., Рулев Ю.К. Экспериментальное исследование теплообмена поверхностей металлов и кварца с недорасширенными струями диссоциированного азота в ВЧ-плазмотроне // Физико-химическая кинетика в газовой динамике. 2015. Т.16, вып. 2. http://chemphys.edu.ru/issues/2015-16-2/articles/537/

7. Жестков Б.Е., Терентьева В.С. Исследование многофункционального покрытия МАИ Д5, предназначенного для защиты особо жаропрочных материалов//Металлы, 2010. № 1. С. 39-48.

8. Жестков Б.Е., Книвель А.Я. Экспериментальное исследование гетерогенной рекомбинации // Труды ЦАГИ. 1981. Вып. 2111. С. 215-227.

9. Андронова Ю.И., Жестков Б.Е. Макаров И.Г., Литвин А.С. Определение каталитических свойств материалов из тепловых измерений//В сборнике “Аэротермодинамика воздушно-космических систем”, изд. ЦАГИ, 1992, часть 1. С. 209-216. 
10. Shvedchenko V.V., Zhestkov B.E., Fischer W.P.P., Ebeling W.D. Methodology and Results of Catalycity and Plasma Erosion Tests on FEI Components // 1994. SAE Technical Paper 941586.

11. Zhestkov B.E., Ivanov D.V., Shvedchenko V.V., Yegorov I.V. et al. Heat Flux Determination to Flat and Wavy FEI Surface // 1998, ESA-WPP-141, pp. 71-81.

12. Zhestkov B.E., Ivanov D.V., Shvedchenko V.V., Yegorov I.V., Fischer W.P.P., Antonenko J., 36924747300.

13. Zhestkov B.E., Yegorov I.V., Fischer W.P.P., Antonenko J. Wind tunnel catalyticity evaluation for thermoprotective elements. // ICES Paper 2001-01-2384.

14. Егоров И.В., Жестков Б.Е., Шведченко В.В. Определение каталитической активности материалов при высоких температурах в гиперзвуковой трубе ВАТ-104. // Ученые записки ЦАГИ. 2014. T. XLV, № 1. C. 3-13.

15. Жестков Б.Е. Исследование термохимической устойчивости теплозащитных материалов. // Ученые записки ЦАГИ. 2014. Т. XLV, № 5. С. 62-77.

16. Vaganov, A.V., Zhestkov, B.E., Lyamin, Yu.B., Poilov, V.Z., Pryamilova, E.N.: Methodology of investigation of ultra high temperature ceramics thermochemical stability and catalycity //AIP Conference Proceedings 1770, 030097 (2016); doi: 10.1063/1.4964039.

17. Kablov, E. N., Zhestkov, B.E., Grashchenkov, D.V., Sorokin, O. Ju., Lebedeva, Ju.E. and Vaganova, M.L.: Investigation of the Oxidative Resistance of the High-Temperature Coating on a sic Material under Exposure to High-Enthalpy Flow. High Temperature. 2017. Vol. 55, no.6. Pp. 873-879.

18. Zhestkov, B.E., Vaganova, M.L., Lebedeva, Ju.E., Sorokin, O. Ju Influence of nitrogen high speed flow exposure on the microstructure and surface chemistry of a coated $\mathrm{SiC}$ composite. High Temperature. 2018. Vol. 56, no.6. Pp. 857-863.

19. Мошаров В.Е., Радченко В.Н., Сенюев И.В. Пирометрия с использованием П.З.С. камер // Приборы и техника эксперимента. 2013. № 4. С. 132-137.

20. Сенюев И.В. Применение спектральной пирометрии в аэродинамическом эксперименте для измерения температуры поверхности и пламени. // Ученые записки ЦАГИ. 2017. Т. XLVIII, №2. C. 50-61.

21. Казаков В.А., Сенюев И.В. Измерение распределения температуры на поверхности образца при испытаниях в тепловых аэродинамических трубах//Труды МАИ. 2017. № 94 . http://trudymai.ru/published.php?ID $=81065$

22. Afonina N.E., Gromov V.G., Sakharov V. I. HIGHTEMP technique of high temperature gas flows numerical simulations // Proc. 5th Europ. Symp. on Aerothermodyn. Spase Vehicles. Cologne, Germany, 2004. SP 563. Noordwijk: ESTEC, 2004. Pp. 323-328.

23. Сахаров В.И. Численное моделирование термическии химически неравновесных течений и теплообмена в недорасширенных струях индукционного плазмотрона // Изв. РАН. МЖГ. 2007. № 6. C. 157-168.

24. Afonina N.E., Gromov V.G., Sakharov V. I. HIGHTEMP technique of high temperature gas flows numerical simulations // Proc. 5th Europ. Symp. on Aerothermodyn. Spase Vehicles. Cologne, Germany, 2004. SP 563. Noordwijk: ESTEC, 2004. Pp. 323-328.

Статья поступила в редакцию 26 сентября 2019 г. 